\title{
A taspine derivative supresses Caco-2 cell growth by competitively targeting EphrinB2 and regulating its pathway
}

\author{
BINGLING DAI, WENJIE WANG, YUJIAO MA, RUI LIU and YANMIN ZHANG \\ School of Pharmacy, Health Science Center, Xi'an Jiaotong University, Xi'an, Shaanxi 710061, P.R. China
}

Received February 2, 2016; Accepted March 112016

DOI: $10.3892 / o r .2016 .4960$

\begin{abstract}
Colorectal cancer is a common gastrointestinal malignancy worldwide and it is a lethal and aggressive malignancy with a dismal prognosis. In the present study, we investigated the effect of taspine derivative $12 \mathrm{k}$ on human colorectal cancer targeted at EphrinB2 and its PDZ. The results indicated that $12 \mathrm{k}$ could bind to EphrinB2 and showed a higher suppressive effect on EphrinB2/HEK293 than on HEK 293 cells. Caco-2 cells were screened for high expression of EphrinB2. We found that $12 \mathrm{k}$ not only significantly decreased Caco-2 cell viability and colony formation but impaired migration. Meanwhile, 12k effectively inhibited blood vessel formation in a tissue model of angiogenesis. Mechanistic studies revealed that $12 \mathrm{k}$ significantly reduced the phosphorylation of EphrinB2 and PDZ protein PICK1. Accordingly, it was associated with the downregulation by $12 \mathrm{k}$ of the PI3K/AKT/mTOR and MAPK signaling pathways which were downstream of VEGFR2, yet it had no effect on VEGFR3. Moreover, the expression of CD34, CD45 and HIF-1 $\alpha$ were downregulated in the Caco- 2 cells. In conclusion, our findings showed that $12 \mathrm{k}$ had an inhibitory effect on the growth of Caco-2 cells, and it functioned by interrupting the phosphorylation of EphrinB2 and its related signaling pathway.
\end{abstract}

\section{Introduction}

Angiogenesis is the formation of new blood vessels sprouting from pre-existing vasculature and is also associated with both physiological processes (wound healing, tissue remodeling

Correspondence to: Dr Yanmin Zhang, School of Pharmacy, Health Science Center, Xi'an Jiaotong University, 76 Yanta West Street, No. 54, Xi'an, Shaanxi 710061, P.R. China

E-mail: zhang2008@mail.xjtu.edu.cn

Abbreviations: CRC, colorectal cancer; EGF, epidermal growth factor; ERK, extracellular signal-regulated kinase; FGF, fibroblast growth factor; MAPK, mitogen-activated protein kinase; PI3K, phosphotidylinositol 3-kinase; VEGF, vascular endothelial growth factor

Key words: 12k, Caco-2 cells, EphrinB2, signaling pathway and developmental progress) and pathological processes (tumor growth, metastasis and coronary artery disease) $(1,2)$. It includes primary existing capillary sprouting, branching and remodeling into a mature blood vessel network (3). In adulthood, angiogenesis is stimulated at sites of tissue repair and in diseases constituting enhanced angiogenesis (4). Moreover, angiogenesis plays an important role in solid tumors and is regulated by protease-mediated degradation of matrix proteins releasing angiogenic factors such as vascular endothelial growth factor (VEGF), epidermal growth factor (EGF), and fibroblast growth factor (FGF), followed by the activation and proliferation of endothelial cells to sprout new vessels $(5,6)$.

EphrinB2 is a membrane-bound ligand that is expressed on arterial endothelial cells (7). It has an intracellular domain and possesses an intrinsic signaling capacity called 'reverse signaling' $(8,9)$. EphrinB2 'reverse signaling' is triggered by its intracellular domain, which comprises several sites for tyrosine, serine phosphorylation and a C-terminal PDZ-binding motif (10). The 'reverse' signal transduction pathway mediated by PDZ-binding motif is an important factor for the formation of the vascular system (11). Thus, inhibition of phosphorylation- or PDZ-dependent signaling downstream of EphrinB ligands prevents endothelial cell sprouting. EphB and EphrinB not only undergo internalization of themselves but promote the internalization of the surrounding membrane and other proteins (12). For example, EphrinB2 signaling has been reported to promote the internalization of VEGFR2 and VEGFR3, and the PDZ-binding motif is critical in this process. Hence, inhibition of EphrinB2 may be useful to simultaneously interfere with the function of VEGFR2 and VEGFR3 which act together during angiogenesis (13). EphrinB2 stimulation can also regulate VEGF/VEGFR signaling in the context of cancer, resulting in the activation of phosphatidylinositol 3-kinase (PI3K)/AKT and extracellular signal-regulated kinase-mitogen-activated protein kinase (ERK-MAPK) pathways. These signaling pathways regulate important cellular functions including endothelial cell proliferation, migration and angiogenesis $(14,15)$.

EphrinB2 ligand expressed in various tumor cells is related to its high vascularity. In the present study, we investigated the effect of taspine derivate 12k (Fig. 1A) which was synthesized with taspine as a lead compound bearing a biphenyl scaffold on colorectal cancer cells Caco-2 for high expression of EphrinB2 (16). Previously, 12k has been reported to have potent anticancer activity. Based on the promising results, we 
further investigated the antitumor activity of $12 \mathrm{k}$ on the tumor growth and migration of human colorectal cancer cells Caco-2 and the related mechanism.

\section{Materials and methods}

Chemicals and reagents. Taspine derivate $12 \mathrm{k}$ (purity $>98 \%$ ) was synthesized in the Research and Engineering Center for Natural Medicine, Xi'an Jiaotong University. Dulbecco's modified Eagle's medium (DMEM), methyl thiazolyl tetrazolium (MTT), dimethylsulphoxide (DMSO) and fibrinogen from bovine plasma were obtained from Sigma-Aldrich (St. Louis, MO, USA). Fetal bovine serum (FBS) was purchased from HyClone (Logan, UT, USA). Trypsin was obtained from Amresco (Solon, OH, USA). Penicillin was purchased from Harbin General Pharmaceutical Factory (Harbin, China), and streptomycin was purchased from North China Pharmaceutical (Shijiazhuang, China). Thrombin was obtained from Guoao Pharmaceutical (Changchun, China). G418 was obtained from Gibco (Carlsbad, CA, USA). Crystal violet was purchased from Beijing Chemical Plant (Beijing, China). PI3K p110 $\alpha$ rabbit $\mathrm{mAb}$, PI3K p110 $\beta$ rabbit $\mathrm{mAb}$, PI3K p110 $\gamma$ rabbit $\mathrm{mAb}, \mathrm{PI} 3 \mathrm{~K}$ class III rabbit $\mathrm{mAb}, \mathrm{p}-\mathrm{PI} 3 \mathrm{~K}$ p85/p55 rabbit mAb, PI3K p85 rabbit mAb, p44/42 MAPK (ERK1/2) rabbit mAb, phospho-p44/42 MAPK (p-ERK1/2) rabbit $\mathrm{mAb}$ and phospho-mTOR rabbit $\mathrm{mAb}$ were all purchased from Cell Signaling Technology (Boston, MA, USA). Phospho-EphrinB2 rabbit polyclonal antibody was purchased from Abcam (Cambridge, UK). PTEN rabbit mAb, $\mathrm{RAC1}$ rabbit $\mathrm{mAb}, \mathrm{CD} 34$ rabbit polyclonal antibody, PICK1 rabbit polyclonal antibody, syntenin rabbit polyclonal antibody, VEGFR3 rabbit polyclonal antibody, CD45 rabbit polyclonal antibody and mTOR polyclonal antibody were obtained from Proteintech Group, Inc. (Chicago, IL, USA). AKT rabbit $\mathrm{mAb}$, phospho-AKT rabbit $\mathrm{mAb}, \mathrm{HIF}-1 \alpha$ rabbit $\mathrm{mAb}$ and EphrinB2 rabbit $\mathrm{mAb}$ were purchased from Epitomics, Inc. (Burlingame, CA, USA). Rabbit anti-GAPDH, goat anti-rabbit IgG, BCA protein assay reagent kit and Enhanced Chemiluminescent (ECL) Plus Reagent kit were obtained from Pierce Biotechnology (Rockford, IL, USA). Protease inhibitor cocktail and phosphatase inhibitor cocktail were purchased from Roche Technology (Basel, Switzerland).

Cell culture and animals. Human colon cancer cell lines LoVo and Caco-2 were purchased from the Shanghai Institute of Biochemistry and Cell Biology of the Chinese Academy of Sciences (Shanghai, China). HEK293 cells were obtained from Professor Xu Li (School of Medicine, Xi'an Jiaotong University). The EphrinB2/HEK293 cell line which overexpresses EphrinB2 was constructed at the Research and Engineering Center for Natural Medicine, Xi'an Jiaotong University. LoVo, Caco-2 and HEK293 cells were cultured in DMEM supplemented with 10\% FBS. The EphrinB2/HEK293 cells were maintained in DMEM supplemented with $10 \%$ FBS and $200 \mathrm{mg} / \mathrm{ml} \mathrm{G} 418$. All cell lines were incubated in a humidified atmosphere of $5 \% \mathrm{CO}_{2}$ at $37^{\circ} \mathrm{C}$.

Mice (4-6 weeks old, body weight 15-18 g) were purchased from the Animal Experimental Center of Xi'an Center of Xi'an Jiaotong University. The mice were maintained under laminar air flow conditions with a $12 \mathrm{~h}$ light/12 h dark cycle.
Laboratory food and water were freely available. Animal care was in accordance with the National Institute of Health guidelines and the Animal Experimental Committee of Xi'an Jiaotong University (SYXK shaan 2015-002).

Preparation of CMSP. Exponentially growing EphrinB2/HEK293 and HEK293 cells were harvested and washed with $5 \mathrm{mM}$ PBS three times, and the precipitate was suspended with $50 \mathrm{mM}$ Tris- $\mathrm{HCl}$ (pH 7.4), followed by ultrasonic destruction for $30 \mathrm{~min}$. The homogenate was centrifuged at $1,000 \mathrm{x} \mathrm{g}$ for $10 \mathrm{~min}$, the supernatant was removed and the homogenate was next centrifuged at 12,000 $\mathrm{x} g$ for $10 \mathrm{~min}$. The precipitate was then suspended with $5 \mathrm{mM}$ PBS. The CMSP was prepared by adsorption of the cell membrane suspension $(5 \mathrm{ml})$ on activated silica $(0.05 \mathrm{~g})$ under vacuum and with gentle agitation. The CMSP was incubated overnight and then washed with $5 \mathrm{mM}$ PBS five times. Finally, the mixture obtained was packed into a column $(10 \times 2.0 \mathrm{~mm}$ i.d.) using a wet packing method (10 $\mathrm{MPa}, 5 \mathrm{~min})$. All the procedures were performed at $4^{\circ} \mathrm{C}$. CMC analysis was performed on a Shimadzu LC-20A apparatus that consisted of two LC-20AD pumps, a DGU-20A3 degasser, an SIL-20A autosampler, a CTO-20A column oven, and an SPD-M20A diode array detector (Shimadzu, Kyoto, Japan). The data were acquired using LC solution software (Shimadzu). The detection wavelength was $250.4 \mathrm{~nm}$. The chromatographic conditions were as follows: CMC column, 10.0x2.0 mm; flow rate, $0.6 \mathrm{ml} / \mathrm{min}$; column temperature, $37^{\circ} \mathrm{C}$; mobile phase, $50 \mathrm{mM}$ phosphate-buffered saline, $\mathrm{pH}$ 7.4.

Fluorescence localization competitive antagonism assay. Exponentially growing EphrinB2/HEK293 cells were plated into a 96-well plate at a density of 5,000 cells/well and cultivated overnight. Then $12 \mathrm{k}$ at different concentrations $(1.5,3$, $6 \mu \mathrm{mol} / \mathrm{l})$ and EphB4-Fc $(0.04 \mathrm{mg} / \mathrm{l})$ were added for $4-8 \mathrm{~h}$ at $37^{\circ} \mathrm{C}$. Cells were washed with PBS, fixed with $4 \%$ paraformaldehyde for $15 \mathrm{~min}$ and treated with $1 \%$ Triton X-100 for $8 \mathrm{~min}$ at room temperature. Finally, the cells were stained with Hoechst 33258 for 15-20 min. All images were recorded under a inverted fluorescence microscope.

Cell viabilityassay.Exponentially growing EphrinB2/HEK293, HEK293, LoVo and Caco-2 cells were seeded into a 96-well plate and cultivated overnight. Then various concentrations of $12 \mathrm{k}$ were added for $48 \mathrm{~h}$. The medium was replaced with $180 \mu \mathrm{l}$ serum-free DMEM and $20 \mu \mathrm{l}$ MTT solution $(5 \mathrm{mg} / \mathrm{ml})$. After a 4-h incubation, the supernatants were removed, and the formazan crystals were dissolved with $150 \mu 1$ DMSO. After being shaken thoroughly for $15 \mathrm{~min}$, the absorbance was measured at $490 \mathrm{~nm}$ on a microplate reader (Bio-Rad, USA). Results are expressed as a percentage of the cell viability ratio. Percentage of cell viability ratio $=\left[1-\left(\mathrm{OD}_{\text {treatment group }}-\mathrm{OD}_{\text {blank }}\right.\right.$ group $\left.) /\left(\mathrm{OD}_{\text {control group }}-\mathrm{OD}_{\text {blank group }}\right)\right]$ x $100 \%$. The experiment was performed in triplicate.

Colony survival assay. Exponentially growing Caco-2 cells were seeded into a 12-well plate (200 cells/well) overnight. Then the cells were treated with $12 \mathrm{k}$ at $0,1.5,3$ and $6 \mu \mathrm{mol} / 1$ and the plate was incubated in a $\mathrm{CO}_{2}$ incubator until the colonies were clearly visible and countable. The colonies 
were fixed with methanol for 15 min and stained with crystal violet for $15 \mathrm{~min}$. After being washed sufficiently, images were captured using enhanced chemiluminescence reagent and the inverted fluorescence microscope. Survival was plotted as the percentage of the surviving cells to the untreated control.

Wound healing assay. Exponentially growing Caco-2 cells were seeded into a 12-well plate and cultivated to grow until $\sim 80 \%$ confluency overnight. Wounds were made by scratching the cells with pipette tips (100-200 $\mu \mathrm{l})$ on the following day. Then $12 \mathrm{k}$ at $0,1.5,3$ and $6 \mu \mathrm{mol} / 1$ was added to allow cells to migrate into the scratched area at different times. The migration of cells was visualized at time $0 \mathrm{~h}$ (after the wound was scratched), 24 and $48 \mathrm{~h}$ after $12 \mathrm{k}$ treatment. The distances of the wound at different concentrations were measured and the migration distances were calculated. Results are expressed as the percentage of the migration rate. Migration rate $=\left(\right.$ Migration distance treatment group $/$ Migration distance $_{\text {control }}$ group) $\mathrm{x} 100 \%$.

Tissue model for angiogenesis. The model was prepared and analyzed using a published method (17). Briefly, mice were sacrificed by cervical dislocation and the lung tissue was separated. After being washed by PBS, lung tissue was cut into pieces $\sim 0.5-1 \mathrm{~mm}^{3}$ and cultured into a 48 -well plate which was coated with lypolymerized fibrinogen with thrombin. After consolidation, additional lypolymerized fibrinogen with thrombin was placed on the lung tissue and different concentrations of $12 \mathrm{k}$ were added. Sprouting vessels were observed under a stereomicroscope on day 5. Neovessel outgrowth was monitored throughout the experiment and imaged using phase microscopy. All aforementioned experiments were conducted on three separate mice and repeated three times.

Western blotting. Caco-2 cells exposed to $12 \mathrm{k}(0,1.5$, $3,6 \mu \mathrm{mol} / \mathrm{l}$ ) for $48 \mathrm{~h}$ were lysed with cell RIPA buffer containing protease inhibitor and phosphatase inhibitor on ice for $30 \mathrm{~min}$. The insoluble protein lysate was harvested followed by ultrasonic destruction for $30 \mathrm{~min}$. Then the lysate was centrifuged at $12,000 \mathrm{rpm}$ for $10 \mathrm{~min}$ at $4^{\circ} \mathrm{C}$. Protein concentration was determined by the BCA protein quantification kit according to the manufacturer's instructions. The cell lysates were denatured by boiling with $5 \mathrm{X}$ reducing sample buffer for $5 \mathrm{~min}$ and run on SDS-PAGE gel. After electrophoresis, the separated proteins were transferred to PVDF membranes and blocked with 5\% non-fat milk in TBST buffer for $2 \mathrm{~h}$ at room temperature with continuous agitation. The membranes were then incubated with specific primary antibodies overnight at $4^{\circ} \mathrm{C}$ followed by washing and incubation with secondary antibodies at a dilution of 1:20,000 in TBST buffer for $2 \mathrm{~h}$ at $37^{\circ} \mathrm{C}$. The membranes were then developed with enhanced chemiluminescence (ECL) kit. The Image-Pro Plus software (Image-Pro Plus 5.1; Media Cybernetics, Inc., Rockville, MD, USA) was used to quantify the protein.

Statistical analysis. Data are expressed as the means \pm SEM. Statistical analysis was performed using the statistical software SPSS 18.0 and ANOVA was used to analyze statistical differences between groups under different conditions. $\mathrm{P}<0.05$ was considered statistically significant.

\section{Results}

Effect of $12 k$ on EphrinB2. The elution profiles of $12 \mathrm{k}$ for the EphrinB2/HEK293 and HEK293 cell CMC columns are shown in Fig. 1B. The immobilized receptors EphrinB2 at the surface of the stationary phase $12 \mathrm{k}$ in the effluent could combine with EphrinB2. The retention behavior indicated that $12 \mathrm{k}$ could bind to EphrinB2. Fluorescent competition study was used to determine whether $12 \mathrm{k}$ could competitively bind to the site on EphrinB2 occupied by EphB4, as EphB4 is a well-known ligand. A decrease in the expression of EphB4 was observed (Fig. 1C). This indicated that $12 \mathrm{k}$ could compete with the EphB4 binding of EphrinB2.

We investigated the effect of $12 \mathrm{k}$ on the growth of EphrinB2/HEK293 and HEK293 cells using MTT assay. The results indicated that $12 \mathrm{k}$ inhibited the growth of EphrinB2/HEK293 and HEK293 cells in a dose-dependent manner (Fig. 2A). Furthermore, 12k was more effective in suppressing EphrinB2/HEK293 cell growth than HEK293 cells. The $\mathrm{IC}_{50}$ values of $12 \mathrm{k}$ for EphrinB2/HEK293 and HEK 293 cells at $48 \mathrm{~h}$ were 4.36 and $7.00 \mu \mathrm{mol} / 1$ respectively. Meanwhile, the morphology of the EphrinB2/HEK293 and HEK 293 cells treated with $12 \mathrm{k}$ were observed under an inverted microscope (Fig. 2B). Collectively, the CMC assay, fluorescent competition assay and MTT assay showed that $12 \mathrm{k}$ acts mainly on EphrinB2.

$12 k$ inhibits colon cancer cell proliferation and Caco-2 cell colony formation. Colorectal cancer cell lines were screened for high expression of EphrinB2. We examined the levels of EphrinB2 in colorectal cancer cells including Caco-2 and LoVo cells. Western blotting results indicated that the expression of EphrinB2 in the Caco-2 cells was significantly higher than that noted in the LoVo cells (Fig. 3A and B).

We further assessed the effect of $12 \mathrm{k}$ on colon cancer cell growth. The results showed that $12 \mathrm{k}$ significantly inhibited cell proliferation and the $\mathrm{IC}_{50}$ values of $12 \mathrm{k}$ for the LoVo and Caco- 2 cells at $48 \mathrm{~h}$ were 12.01 and $6.73 \mu \mathrm{mol} / 1$ respectively. $12 \mathrm{k}$ showed a higher suppressive effect on the Caco-2 cells than on the LoVo cells (Fig. 3C). Consequently, Caco-2 cells were used for the subsequent experiments.

We also investigated the action of $12 \mathrm{k}$ on Caco- 2 cell colony formation. The results showed that upon 10-15 days of continuous culture, $12 \mathrm{k}$ significantly inhibited the colony formation of the Caco- 2 cells in a dose-dependent manner (Fig. 3D and E). These findings indicate that $12 \mathrm{k}$ has potential antitumor properties in colon cancer cells.

$12 k$ inhibits Caco-2 cell migration. Meanwhile, the ability of $12 \mathrm{k}$ to inhibit the migration of the Caco-2 cells was determined. The results showed that in the absence of $12 \mathrm{k}$, the cells migrated within $48 \mathrm{~h}$ to fill the scratched area, while the treatment of $12 \mathrm{k}$ significantly prevented the migration of the Caco- 2 cells in a dose-dependent manner at 24 and $48 \mathrm{~h}$ (Fig. 4A and B). The wound healing assay validated that $12 \mathrm{k}$ impaired Caco- 2 cell migration.

$12 k$ inhibits angiogenesis in a tissue model of angiogenesis. To evaluate the influence of $12 \mathrm{k}$ on angiogenesis, we used a lung tissue model of angiogenesis as established previously (17). $12 \mathrm{k}$ 

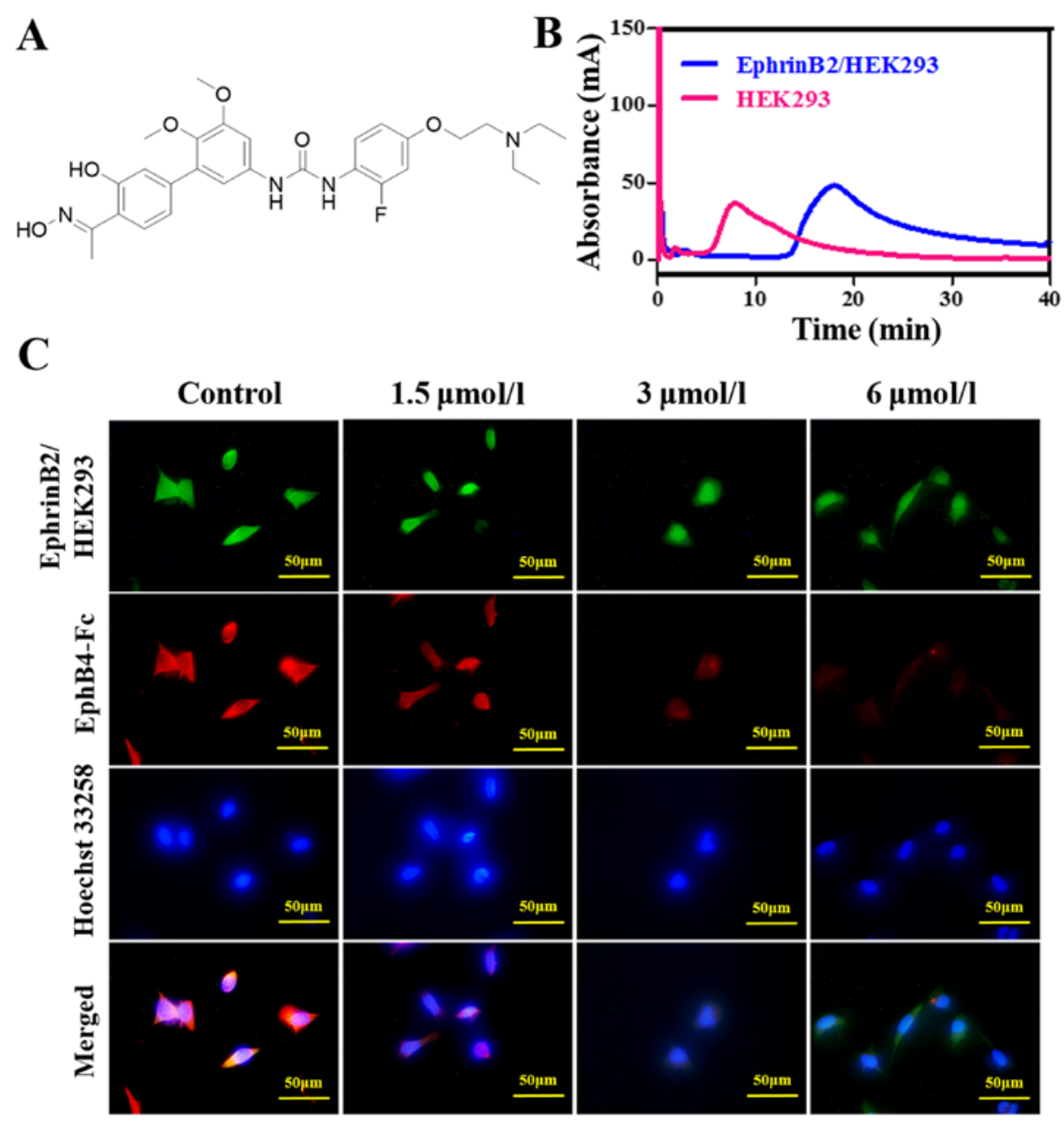

Figure 1. Effect of taspine derivative 12k targeted on EphrinB2. (A) Chemical structure of 12k. (B) CMC chromatograms of 12k for the EphrinB2/HEK293 CMC and HEK293 cell CMC columns. (C) EphrinB2/HEK293 cells were treated without or with $12 \mathrm{k}$ at different concentrations and then cultured with EphB4-Fc for 4-8 h. The subcellular localization of EphB4-Fc was visualized by immunofluorescence analysis.

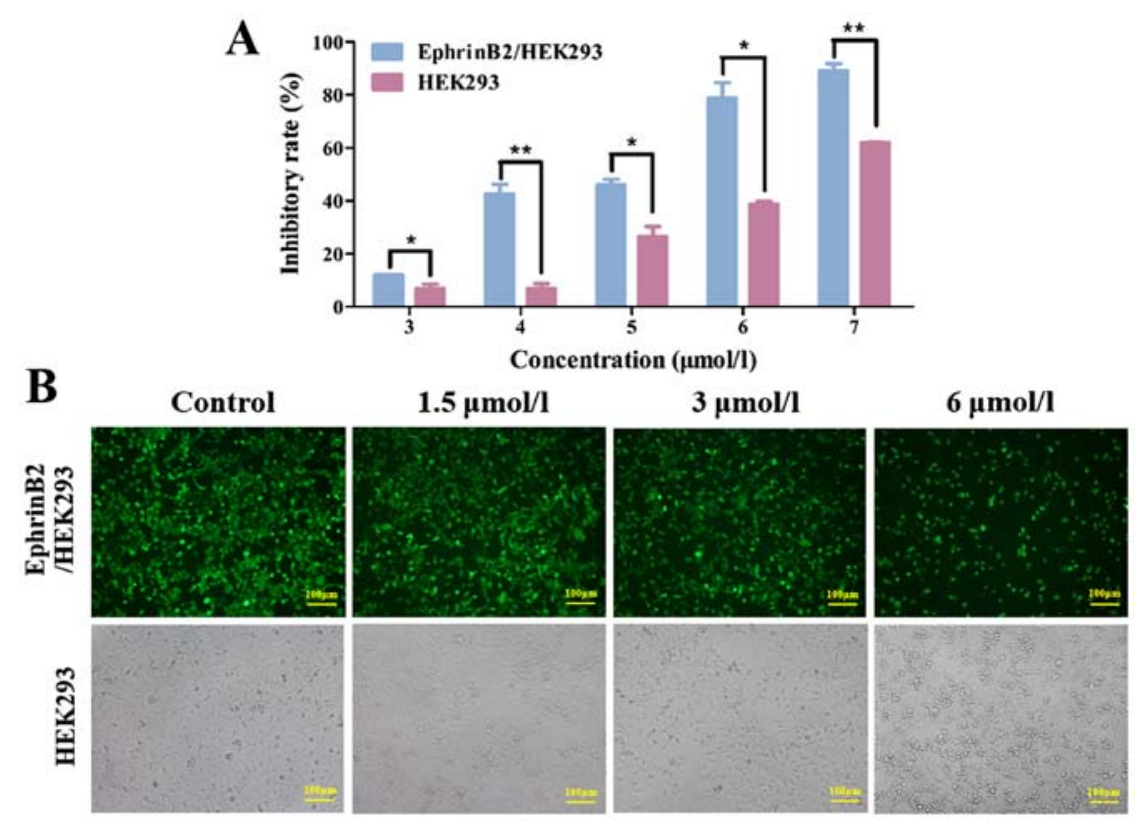

Figure 2. Effect of taspine derivative 12k on EphrinB2/HEK293 and HEK293 cell proliferation and cell morphology. (A) Effect of 12k on the viability of EphrinB2/HEK293 and HEK293 cells. Cells were cultured without or with 12k at the indicated concentrations for 48 h. Cell viability was determined by MTT assay. (B) Effect of 12k at different concentrations on cell morphology of EphrinB2/HEK293 and HEK293 cells. The top row shows EphrinB2/HEK293 cells and the bottom row shows HEK293 cells. 

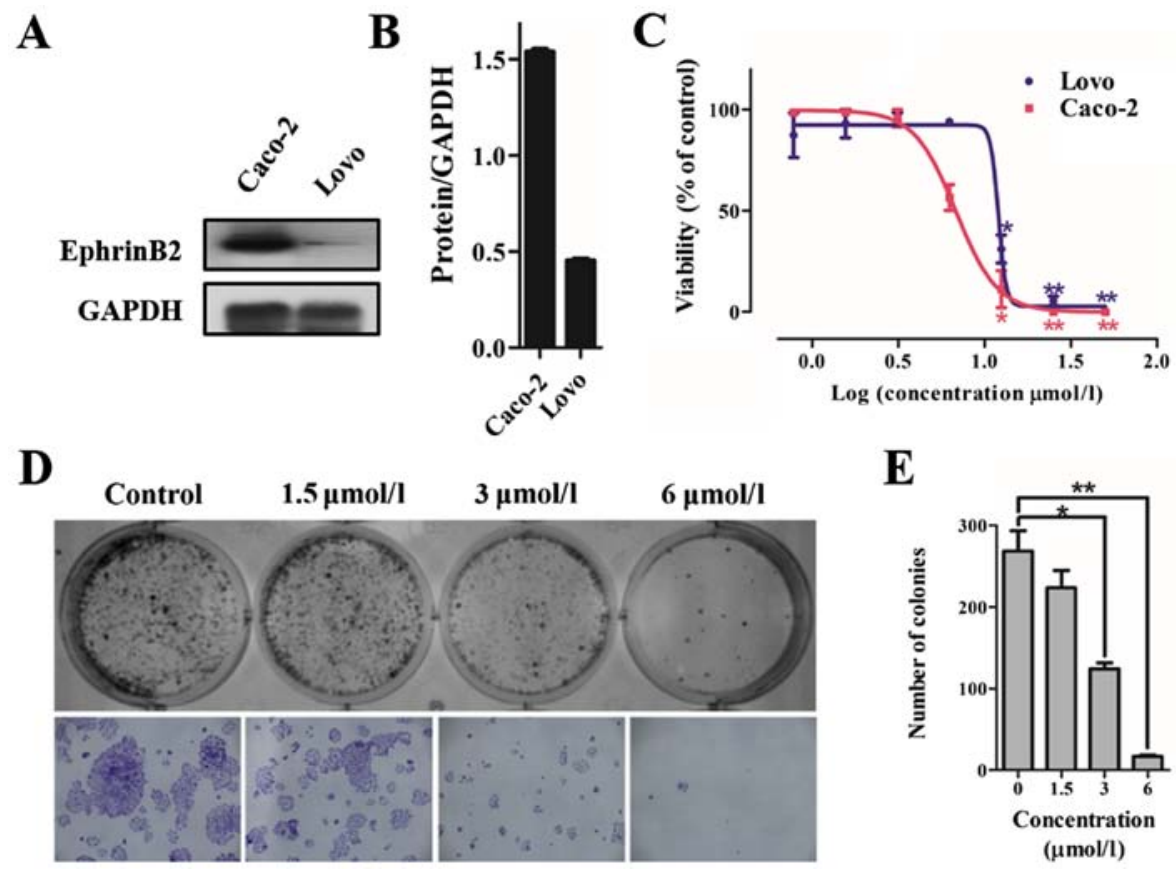

Figure 3. Taspine derivative 12k inhibits colorectal cancer cell proliferation and colony formation. (A) Expression of EphrinB2 in colorectal cancer cells. (B) Quantification of data in the densitometric analysis of the bands from (A). (C) Effect of 12k on the viability of the colorectal cancer cells. Cells were cultured without or with $12 \mathrm{k}$ at the indicated concentrations for $48 \mathrm{~h}$. Cell viability was determined by MTT assay. (D) Effect of $12 \mathrm{k}$ on colony formation of Caco-2 cells. The top row shows the colony formation and the bottom row shows the individual colonies. (E) Quantification of the number of colonies following treatment of the cells with $12 \mathrm{k}$ at different concentrations. Values are presented as means $\pm \mathrm{SEM}(\mathrm{n}=3)$. ${ }^{*} \mathrm{P}<0.05,{ }^{* *} \mathrm{P}<0.01$ vs. the control group.

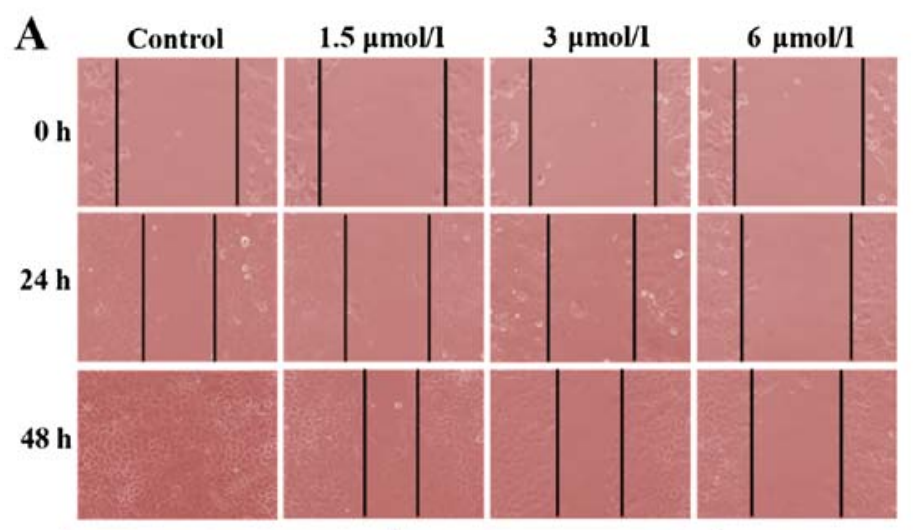

$\mathbf{C}$

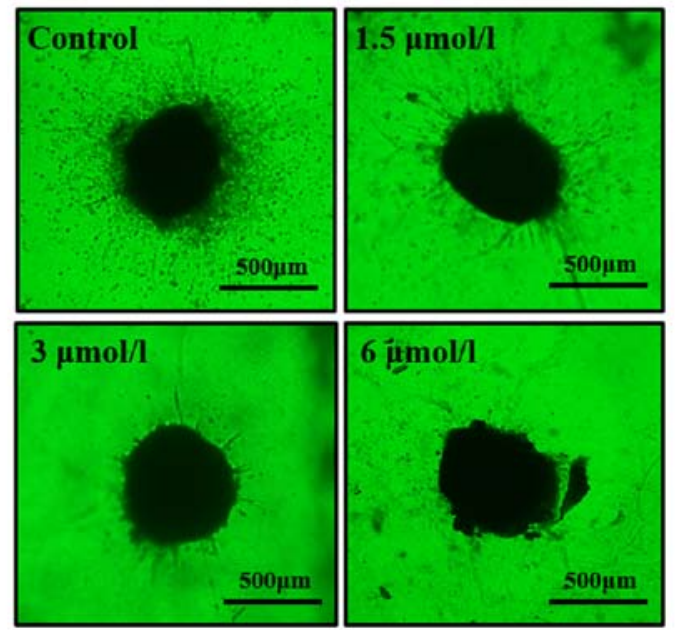

D

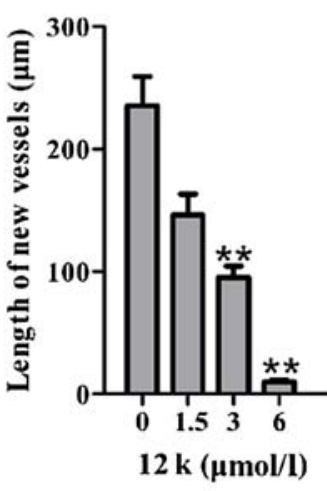

B

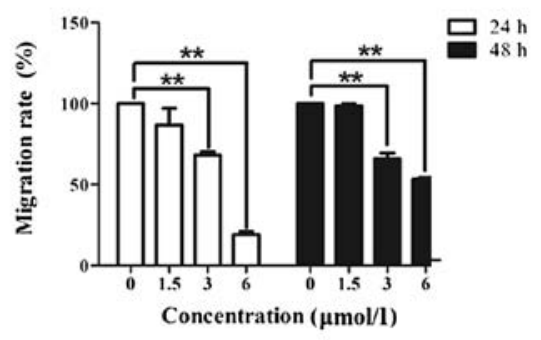

$\mathbf{E}$

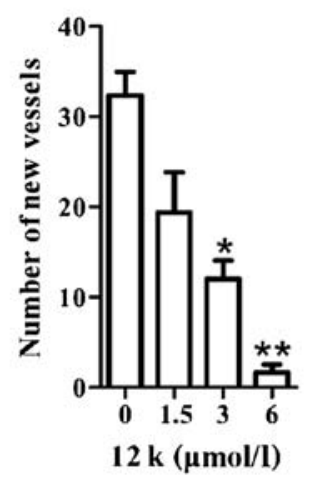

Figure 4. Taspine derivative 12k suppresses Caco-2 cell migration and angiogenesis in a tissue model for angiogenesis. (A) Images of Caco-2 cells that migrated into the scratched wound at 24 and $48 \mathrm{~h}$. (B) Quantitation of data for migration distance (A). (C) The representative images of vessels outgrown from the lung tissue on day 5 in the 12k-treated group; vessels grew normally in the control group while vessels treated with $12 \mathrm{k}$ exhibited a different decrease when compared with the control group. (D) Quantification of the number of microvessels in the 12k-treated group. (E) Quantification of vessel length in the $12 \mathrm{k}$-treated group. Values are presented as the means $\pm \mathrm{SEM}(\mathrm{n}=3)$. ${ }^{*} \mathrm{P}<0.05,{ }^{* *} \mathrm{P}<0.01$ vs. the control group. 
at different concentrations was incubated with the lung tissues. The results showed that $12 \mathrm{k}$ at $1.5,3$ and $6 \mu \mathrm{mol} / 1$ disrupted the formation of vessels outgrown from the periphery of the lung tissues (Fig. 4C). The number and length of the vessels following treatment with $12 \mathrm{k}$ at different concentrations were reduced in a dose-dependent manner (Fig. 4D and E). The findings indicate that $12 \mathrm{k}$ inhibited vessel development in an animal model.

$12 k$ regulates EphrinB2 and PDZ in Caco- 2 cells. Firstly, we detected the effect of $12 \mathrm{k}$ on EphrinB2. The results showed that $12 \mathrm{k}$ effectively downregulated the phosphorylation of EphrinB2 in the Caco-2 cells (Fig. 5A and B). This indicated that $12 \mathrm{k}$ inhibited migration and angiogenesis through regulation of EphrinB2 regulation.

It has been reported that PDZ-binding motif proteins such as syntenin and PICK1 interact with EphrinB2 $(18,19)$. The results showed that treatment of $12 \mathrm{k}$ markedly suppressed the expression of PICK1 in a dose-dependent manner, but had a minimal effect on syntenin (Fig. 5C and D). All things considered, these results demonstrated that $12 \mathrm{k}$ inhibited the phosphorylation of EphrinB2 by mediating the cytoplasmic PDZ-binding motif of PICK1, but had no effect on syntenin.

$12 k$ inhibits VEGFR2 downstream signaling pathways. PDZ-dependent EphrinB2 signaling regulates VEGFR2 activity. VEGFR downstream signaling pathways include both PI3K/AKT/mTOR and MAPK signaling cascades which play an important role in proliferation, survival, angiogenesis, and metastasis of tumor cells by promoting endothelial cell proliferation and migration. In the present study, we further investigated the effect of $12 \mathrm{k}$ on the PI3K/AKT/mTOR and MAPK pathways. As shown in Fig. 6A and E, 12k inhibited the PI3Kp110 $\alpha$, PI3Kp110 $\gamma$ and PI3Kp110III subunit, but upregulated the PI3Kp110 $\beta$ subunit. Meanwhile, phosphorylation of PI3Kp85/p55 was inhibited by $12 \mathrm{k}$ in a concentration-dependent manner (Fig. 6B and F). In addition, activation of the serine/threonine protein kinase AKT and mTOR were also suppressed upon $12 \mathrm{k}$ treatment in the Caco-2 cells (Fig. 6C and F). We then performed western blotting to determine whether $12 \mathrm{k}$ could inhibit the activation of MAPK cascades. As shown in Fig. 6D and F, 12k significantly downregulated the phosphorylation of ERK in the Caco- 2 cells. Our data clearly indicated that $12 \mathrm{k}$ not only inhibits the constitutive activation of the PI3K/AKT/mTOR signaling cascade; but it also inhibits the activation of ERK in Caco-2 cells.

$12 k$ regulates VEGFR3 regulatory molecules. Ephrin $\mathrm{B} 2$ signaling has been reported to promote the internalization of VEGFR2 and VEGFR3. Thus, inhibition of EphrinB2 may simultaneously interfere with the function of VEGFR2 and VEGFR3. Next, we explored the potential role of $12 \mathrm{k}$ in VEGFR3 activation in Caco-2 cells. As shown in Fig. 7A and D, $12 \mathrm{k}$ had no effect on the expression of VEGFR3 and Rac-1.

Effects of $12 k$ on angiogenesis regulatory molecules. The related angiogenesis proteins CD34 and CD45 were downregulated following treatment with $12 \mathrm{k}$ (Fig. 7B and D). PTEN, a negative regulator of the PI3K signaling pathway,

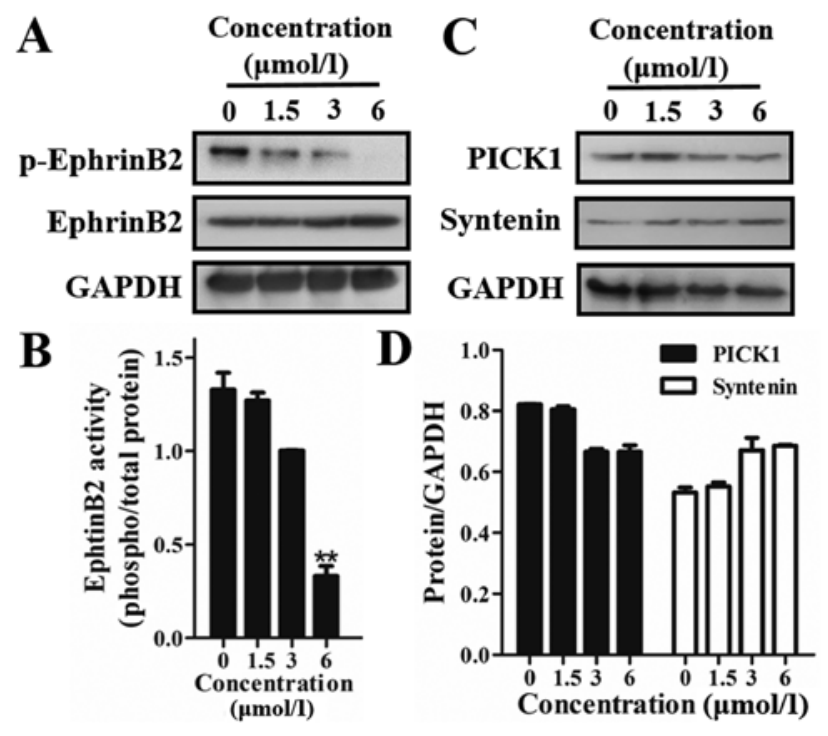

Figure 5. Taspine derivative 12k regulates EphrinB2 activity and its PDZ protein. (A) Effect of 12k on phosphorylation of EphrinB2. (B) Quantified data of the densitometric analysis of the bands from (A). (C) Effect of 12k on PDZ-binding motif proteins of EphrinB2. (D) Quantified data of the densitometric analysis of the bands from (C). Values are presented as the means $\pm \operatorname{SEM}(n=3){ }^{*} \mathrm{P}<0.05,{ }^{* *} \mathrm{P}<0.01$ vs. the control group.

was upregulated while HIF-1 $\alpha$, overexpressed in many human cancers, was reduced by $12 \mathrm{k}$ (Fig. 7C and D).

\section{Discussion}

Colorectal cancer is the most common type of cancer, accounting for $\sim 10 \%$ of all cancer cases (20). Treatments for colorectal cancer include surgery, radiation therapy, chemotherapy and targeted therapy. Recently, drugs targeting key pathways have generated new perspectives for the treatment of colorectal cancer. The EphrinB2 signaling pathway plays a key role in development and postnatal angiogenesis in physiology and disease. Thus, EphrinB2 appears to be a promising prognostic indicator and target to modulate angiogenesis in cancer therapies (8).

In this study, we demonstrated that a novel taspine derivative, $12 \mathrm{k}$, played a significant role in inhibiting proliferation via binding to EphrinB2 and regulating the EphrinB2 signaling pathway. The CMC assay with EphrinB2/HEK293 and HEK293 cells indicated that 12k could bind to EphrinB2. Also fluorescent competition binding assay further validated that $12 \mathrm{k}$ may have direct competition at a single common binding site on EphrinB2. Meanwhile, 12k had a more significant suppressive effect on high EphrinB2-expressing EphrinB2/HEK293 cells than on HEK293 cells. Our experimental findings suggest that $12 \mathrm{k}$ may be effective against EphrinB2.

To explore $12 \mathrm{k}$ as a potential chemotherapeutic agent for the treatment of colorectal cancers, we investigated the expression of EphrinB2 in Caco-2 and LoVo cells, as well as explored the inhibitory effect of $12 \mathrm{k}$ on cell growth. The results demonstrated that $12 \mathrm{k}$ treatment resulted in a reduction in colorectal cell viability and showed a higher suppressive effect on high EphrinB2-expressing Caco-2 cells. Meanwhile, we found that $12 \mathrm{k}$ inhibited Caco- 2 cell colony formation. 


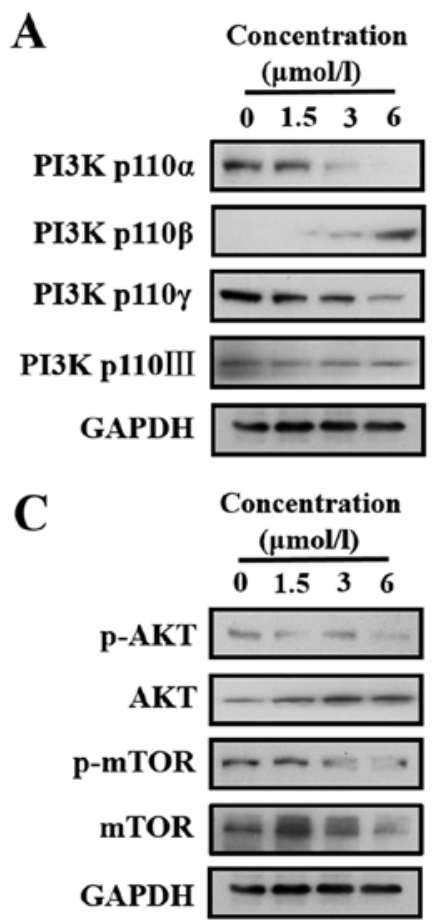

B $\quad$ E

$\mathbf{E}$
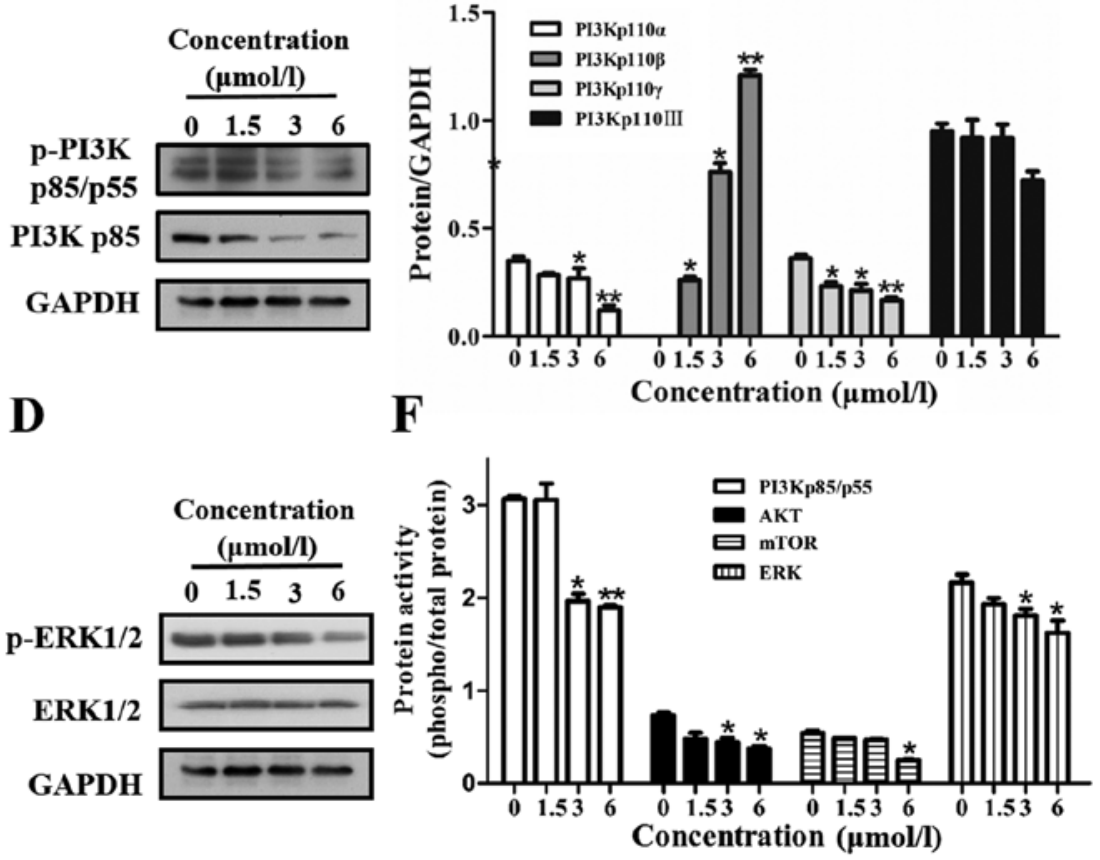

Figure 6. Taspine derivative 12k regulates the PI3K/AKT/mTOR signaling pathway and the MAPK signaling pathway proteins. (A) Effect of $12 \mathrm{k}$ on the PI3K subtype protein expression of PI3K $\alpha$, PI3K $\beta$, PI3K $\gamma$ and PI3KIII by western blotting. (B) Effect of $12 \mathrm{k}$ on the phosphorylation of PI3K p85/p55. (C) Effect of $12 \mathrm{k}$ on the phosphorylation of AKT and mTOR. (D) Effect of $12 \mathrm{k}$ on the phosphorylation of ERK. (E) Quantified data of the densitometric analysis of the bands from (A). (F) Quantified data of the densitometric analysis of the bands from (B-D). Values are presented as the means \pm SEM $(n=3)$. ${ }^{*} \mathrm{P}<0.05$, ${ }^{* *} \mathrm{P}<0.01 \mathrm{vs}$. the control group.

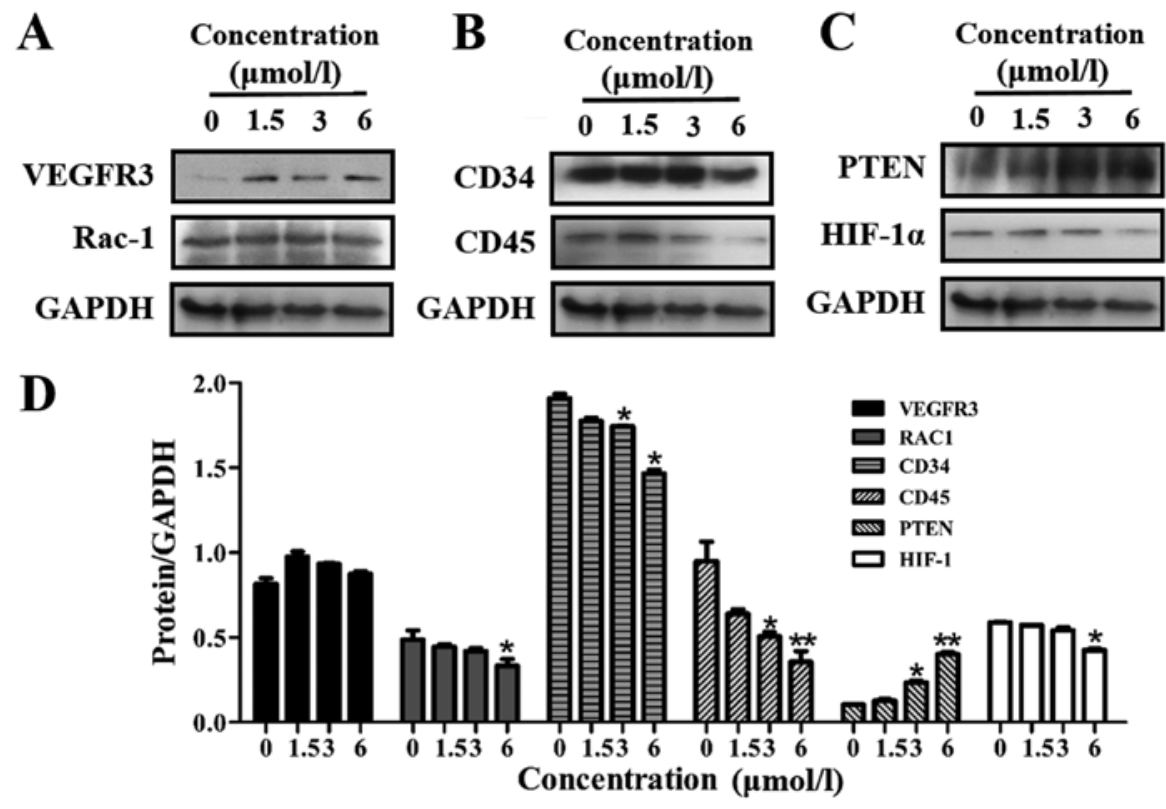

Figure 7. Taspine derivative 12k regulates the VEGFR3 signaling pathway and other related proteins. (A) Effect of 12k on the VEGFR3 signaling proteins. (B) Bands corresponding to CD34 and CD45 in Caco-2 cells. (C) Effect of 12k on PTEN and HIF-1 $\alpha$ protein. (D) Quantified data of the densitometric analysis of the bands from (A-C). Values are presented as the means \pm SEM $(n=3) .{ }^{*} \mathrm{P}<0.05,{ }^{* *} \mathrm{P}<0.01$ vs. the control group.

Moreover, cell migration is important during early invasion and the subsequent metastasis and angiogenesis of a tumor and is responsible for most cancer deaths (21). In the present study, it was confirmed by our experiments that $12 \mathrm{k}$ had a significant inhibitory effect on Caco-2 cell migration. The results also showed that $12 \mathrm{k}$ inhibited the development of neovessels sprouting from the edge of the lung tissues in the tissue model of angiogenesis in vitro.

We subsequently investigated the anti-proliferation mechanism of $12 \mathrm{k}$. Our results initially indicated that $12 \mathrm{k}$ 
downregulated the phosphorylation of EphrinB2 at the protein level. Various reports suggest that EphrinB2 reverse signaling dependent on the C-terminal PDZ-binding motif regulates angiogenic sprouting and branching in pathological angiogenesis. Our results indicated that $12 \mathrm{k}$ suppressed the PDZ-binding motif protein, PICK1, but had a minimal effect on syntenin. Previous findings indicate that EphrinB2 signaling simultaneously induces the internalization of VEGFR2 and VEGFR3. Furthermore, the PI3K/AKT/mTOR and the MAPK signaling pathways, which contribute to the metastasis and angiogenesis of tumor cells, are downstream targets of VEGFR2-mediated signaling. Rac-1 binds to a variety of effector proteins to regulate cellular responses such as epithelial cell polarization. Hence, we further explored the effect of $12 \mathrm{k}$ on the VEGFR2 and VEGFR3 signaling pathways, which act together during angiogenesis. Our results showed that $12 \mathrm{k}$ exhibited inhibitory activity on the expression levels of various isoforms of PI3K catalytic subunits ( $110 \alpha$, $\mathrm{p} 110 \beta$ and $\mathrm{p} 110 \gamma)$ and regulatory subunits (p110 $\alpha$ and $\mathrm{p} 110 \beta$ and $\mathrm{p} 85$ ). At the same time, its downstream effector, Akt, and mTOR activation were also downregulated. In addition, ERK activation in the MAPK/ERK pathway was also suppressed by $12 \mathrm{k}$. Simultaneously, we noted that $12 \mathrm{k}$ had no effect on VEGFR3 and Rac-1. Collectively, 12k reduced the phosphorylation of EphrinB2 by suppressing its PDZ-binding motif protein, PICK1, and also affected the VEGFR2 signaling pathway.

Cluster of differentiation 34 (CD34) is a cell surface glycoprotein, and it functions as a cell-cell adhesion factor (22). CD34 is selectively expressed on capillary endothelial cells and is considered to be an important marker of tissue vascularization. CD45 is correlated with CRC disease stage and outcome (23). Thus, CD34 and CD45 that are related to CRC angiogenesis were also analyzed. Our results showed that $12 \mathrm{k}$ suppressed the expression of CD34 and CD45. PI3K catalyzes the production of phosphatidylinositol-3,4,5-triphosphate by phosphorylating phosphatidylinositol (PI), phosphatidylinositol-4-phosphate (PIP) and phosphatidylinositol-4,5-bisphosphate (PIP2). Growth factors and hormones trigger this phosphorylation event, which in turn coordinates cell growth, cell cycle entry, cell migration and cell survival (24). PTEN reverses this process, and the PI3K signaling pathway is constitutively activated in human cancers that have loss of function of PTEN (25). HIF-1 $\alpha$ is overexpressed in many human cancers (26). HIF-1 $\alpha$ overexpression is heavily implicated in the promotion of tumor growth and metastasis through its role in initiating angiogenesis and regulating cellular metabolism to overcome hypoxia (27). Western blot assay showed that PTEN activity was strongly increased and HIF-1 $\alpha$ activity was decreased.

In conclusion, the results presented in this study demonstrated that $12 \mathrm{k}$ inhibited CRC growth by angiogenesis responses in vitro. Its mechanism involved the downregulation of the activation of EphrinB2 and the PDZ-binding motif protein. Meanwhile, $12 \mathrm{k}$ functioned by reducing the phosphorylation of PI3K, Akt, mTOR and ERK. Furthermore, $12 \mathrm{k}$ downregulated the expression of CD34, CD45 and HIF-1 $\alpha$. These results suggest that $12 \mathrm{k}$ may constitute a novel anti-angiogenic drug that acts by targeting EphrinB2 signaling.

\section{Acknowledgements}

This study was supported by the National Natural Science Foundation of China (grant nos. 81370088 and 81503101), the Fundamental Research Funds for the Central Universities of Zhuizong, the Project of Shaanxi Star of Science and Technology (grant no. 2012Kjxx-06), the National Science Foundation for Post-doctoral Scientists of China (grant no. 2015M570843) and the Supporting Plan for New Century Excellent Talents of the Ministry of Education (grant no. NCET-13-0467).

\section{References}

1. Folkman J: Tumor angiogenesis: Therapeutic implications. N Engl J Med 285: 1182-1186, 1971.

2. Folkman J: Angiogenesis in cancer, vascular, rheumatoid and other disease. Nat Med 1: 27-31, 1995.

3. Folkman J: Tumor angiogenesis: A possible control point in tumor growth. Ann Intern Med 82: 96-100, 1975.

4. Carmeliet P: Mechanisms of angiogenesis and arteriogenesis. Nat Med 6: 389-395, 2000.

5. Ferrara $\mathrm{N}$ and Kerbel RS: Angiogenesis as a therapeutic target. Nature 438: 967-974, 2005.

6. Ferrara N, Gerber HP and LeCouter J: The biology of VEGF and its receptors. Nat Med 9: 669-676, 2003.

7. Salvucci $O$ and Tosato G: Essential roles of EphB receptors and EphrinB ligands in endothelial cell function and angiogenesis. Adv Cancer Res 114: 21-57, 2012.

8. Pitulescu ME and Adams RH: Eph/ephrin molecules - a hub for signaling and endocytosis. Genes Dev 24: 2480-2492, 2010.

9. Pasquale EB: Eph-ephrin bidirectional signaling in physiology and disease. Cell 133: 38-52, 2008.

10. Chrencik JE, Brooun A, Recht MI, Kraus ML, Koolpe M, Kolatkar AR, Bruce RH, Martiny-Baron G, Widmer H, Pasquale EB, et al: Structure and thermodynamic characterization of the EphB4/Ephrin-B2 antagonist peptide complex reveals the determinants for receptor specificity. Structure 14: 321-330, 2006.

11. Sawamiphak S, Seidel S, Essmann CL, Wilkinson GA, Pitulescu ME, Acker T and Acker-Palmer A: Ephrin-B2 regulates VEGFR2 function in developmental and tumour angiogenesis. Nature 465: 487-491, 2010.

12. Wang Y,Nakayama M, Pitulescu ME, Schmidt TS, Bochenek ML, Sakakibara A, Adams S, Davy A, Deutsch U, Lüthi U, et al: Ephrin-B2 controls VEGF-induced angiogenesis and lymphangiogenesis. Nature 465: 483-486, 2010.

13. Gomez MC, Bravo GB, Caceres CG, Gongora A and Baldi A: The eph/ephrin system, an example of versatility and functional diversity in molecular biology of cancer and angiogenesis. Acta Bioquim Clin Latinoam 4: 675-679, 2011.

14. Steinle JJ, Meininger CJ, Chowdhury U, Wu G and Granger HJ: Role of ephrin B2 in human retinal endothelial cell proliferation and migration. Cell Signal 15: 1011-1017, 2003.

15. Maekawa H, Oike Y, Kanda S, Ito Y, Yamada Y, Kurihara H, Nagai R and Suda T: Ephrin-B2 induces migration of endothelial cells through the phosphatidylinositol-3 kinase pathway and promotes angiogenesis in adult vasculature. Arterioscler Thromb Vasc Biol 23: 2008-2014, 2003.

16. Gao H, Su P, Shi Y, Shen X, Zhang Y, Dong J and Zhang J: Discovery of novel VEGFR-2 inhibitors. Part II: Biphenyl urea incorporated with salicylaldoxime. Eur J Med Chem 90: 232-240, 2015.

17. Dai B, Zhang Y, Zhan Y, Zhang D, Wang N and He L: A novel tissue model for angiogenesis: Evaluation of inhibitors or promoters in tissue level. Sci Rep 4: 3693, 2014.

18. Grootjans JJ, Reekmans G, Ceulemans H and David G: Syntenin-syndecan binding requires syndecan-synteny and the co-operation of both PDZ domains of syntenin. J Biol Chem 275: 19933-19941, 2000.

19. Dev KK: PDZ domain protein-protein interactions: A case study with PICK1. Curr Top Med Chem 7: 3-20, 2007.

20. Thorat MA and Cuzick J: Role of aspirin in cancer prevention. Curr Oncol Rep 15: 533-540, 2013. 
21. Lou L, Ye W, Chen Y, Wu S, Jin L, He J, Tao X, Zhu J, Chen X, Deng A, et al: Ardipusilloside inhibits survival, invasion and metastasis of human hepatocellular carcinoma cells. Phytomedicine 19: 603-608, 2012.

22. Nielsen JS and McNagny KM: Novel functions of the CD34 family. J Cell Sci 121: 3683-3692, 2008.

23. Chew A, Salama P, Robbshaw A, Klopcic B, Zeps N, Platell C and Lawrance IC: SPARC, FOXP3, CD8 and CD45 correlation with disease recurrence and long-term disease-free survival in colorectal cancer. PLoS One 6: e22047, 2011

24. Cantley LC: The phosphoinositide 3-kinase pathway. Science 296: 1655-1657, 2002.
25. Simpson L and Parsons R: PTEN: Life as a tumor suppressor. Exp Cell Res 264: 29-41, 2001.

26. Zhong H, De Marzo AM, Laughner E, Lim M, Hilton DA, Zagzag D, Buechler P, Isaacs WB, Semenza GL and Simons JW: Overexpression of hypoxia-inducible factor 1alpha in common human cancers and their metastases. Cancer Res 59: 5830-5835, 1999.

27. Bos R, van der Groep P, Greijer AE, Shvarts A, Meijer S Pinedo HM, Semenza GL, van Diest PJ and van der Wall E: Levels of hypoxia-inducible factor-1alpha independently predict prognosis in patients with lymph node negative breast carcinoma. Cancer 97: 1573-1581, 2003. 